\title{
PARAPHARYNGEAL BRANCHIAL CLEFT CYST: A CASE REPORT
}

\section{Marcele Oliveira dos Santos ${ }^{1}$, Adriana Muradás Girardi ${ }^{1}$, Fábio Muradás Girardi², Luiz Alberto Hauth², Viliam Gustavo Weber ${ }^{3}$}

A 30-year-old woman presented with a 2-year history of right-sided pharyngeal foreign body sensation. There were no signs of dysarthria, dysphagia, odynophagia, or dyspnea. On physical examination, we observed a fluctuant, painless mass in the oropharynx, pressing against the right lateral pharyngeal wall, covered with normal mucosa. Full examination of the head and neck, including cranial nerve evaluation, detected no further abnormalities. A cranial Computerized Tomography (CT) revealed a $53 \times 41 \times 26-\mathrm{mm}$ cystic mass filling the right prestyloid parapharyngeal space (figure 1). Magnetic resonance imaging (MRI) revealed an iso- or slightly hypo-signal intensity of the lesion on T1 (figure 2) and a mixed signal intensity with hyper- and iso-signal intensity on T2. The patient underwent surgery using transcervical approach. After decompression with aspiration using an 18-gauge needle, total excision of the lesion was performed. Thick and yellowish material was aspirated from the mass (figure 3 ). The cyst contained a highly proteinaceous mucinous fluid. Histopathological examination of the cyst wall showed a single layer of ciliated columnar epithelium with lymphoid infiltrate. The diagnosis of branchial cleft cyst (BCC) was confirmed. The patient recovered without any complications and experienced complete resolution of her symptoms.

Tumors of the parapharyngeal space are rare, accounting for $0.5 \%$ of head and neck neoplasms. Approximately $40 \%$ to $50 \%$ of masses in this location derive from salivary gland tumors. Other common lesions in this space include neurogenic tumors (17\%-25\%) and paragangliomas (10\%-15\%). A heterogeneous group of lesions, including lymph nodes, chordomas, hematogenous tumors, inflammatory lesions, and BCCs represent the remaining parapharyngeal masses $(10 \%-33 \%)^{1}$.

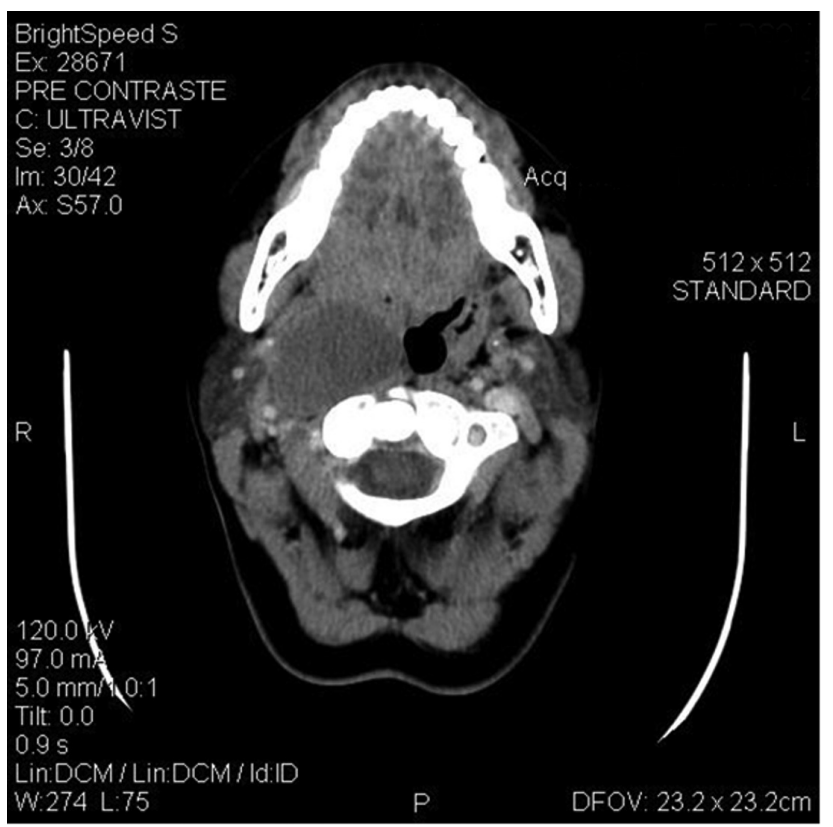

Figure 1: CT: cystic mass filling the right prestyloid parapharyngeal space.
Clin Biomed Res. 2015;35(1):61-62 1 Faculdade de Medicina, Universidade Federal do Rio Grande do Sul (UFRGS). Porto Alegre, RS, Brazil.

2 Serviço de Cirurgia de Cabeça e Pescoço, Hospital Ana Nery. Santa Cruz do Sul, RS, Brazil.

3 Faculdade de Medicina, Universidade de Santa Cruz do Sul (UNISC). Santa Cruz do Sul, RS, Brazil.

Corresponding author: Adriana Muradás Girardi E-mail: adriana.m.girardi@gmail.com Universidade Federal do Rio Grande do Sul

Av. Independência, 354, apto. 1602. 90035-070, Porto Alegre, RS, Brazil. 


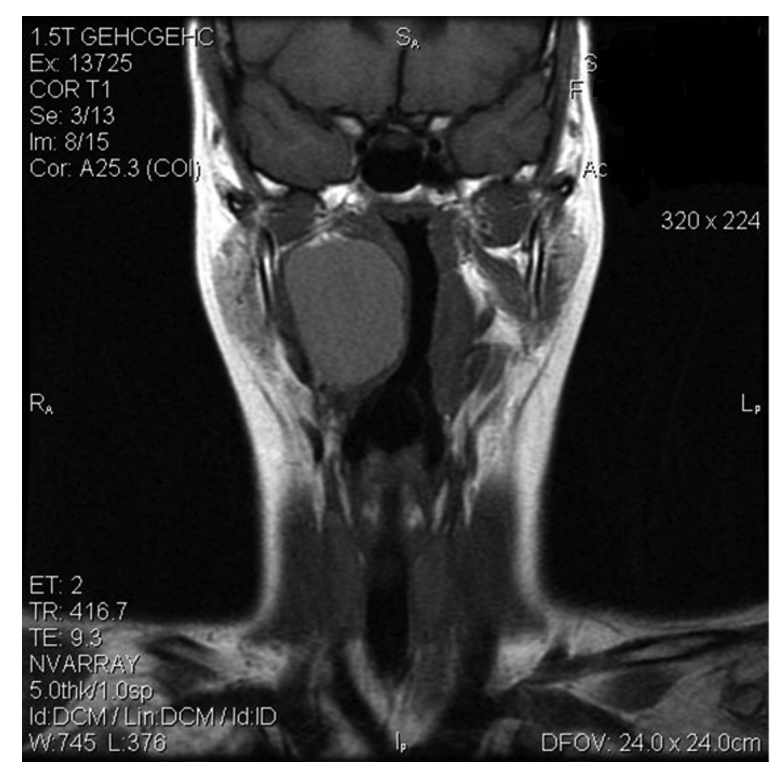

Figure 2: MRI: iso- or slightly hypo-signal intensity of the lesion in T1.

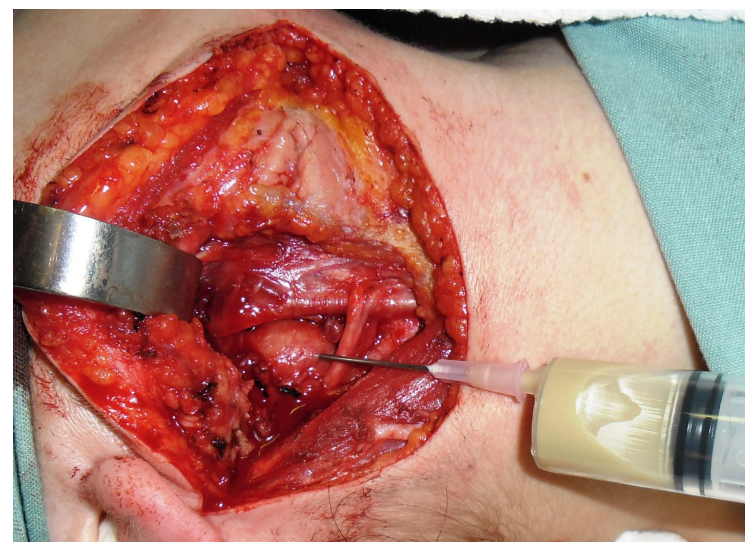

Figure 3: Intraoperative puncture lesion showed dense yellowish content with debris.
Parapharyngeal tumors expand to the least resistant soft tissue planes, appear as submucosal lateral pharyngeal masses protruding intraluminally, or extending to the skull base. The most common symptoms are hearing loss due to middle ear effusion, sore throat, dysphagia, and dysarthria.

The origin of a tumor of the parapharyngeal space may often be determined with significant accuracy on preoperative imaging. A combination of a CT scan with contrast and MRI with gadolinium enhancement is the gold standard test. Such images make it possible for the surgeon to determine the size, precise location, and likely origin of these tumors ${ }^{2}$. Generally, prestyloid tumors are minor salivary gland neoplasms, whereas post-styloid tumors are usually neurogenic neoplasms. The role of pre-operative fine needle aspiration (FNA) in the routine diagnostic workup is controversial ${ }^{3}$. Despite advances in radiographic images, surgical excision remains the definitive technique for the diagnosis of parapharyngeal space tumors.

The present manuscript reports on a parapharyngeal BCC, a rare presentation of a common head and neck pathology. BCCs are the most common cystic neck masses in adults ${ }^{4}$. Most BCCs arise from the second branchial apparatus. Second BCCs can occur anywhere from the tonsillar fossa to the supraclavicular area. Parapharyngeal location is extremely rare $^{5}$. MRI signal intensity may vary depending on the protein content of the cyst. Complete excision is necessary to avoid recurrences. Approaches to the lesions are dependent on the location, extent of the lesions, and patient-related factors. External surgical approach to tumors of the parapharyngeal space is the best choice.

\section{REFERENCES}

1. Carrau RL, Myers EN, Johnson JT. Management of tumors arising in the parapharyngeal space. Laryngoscope. 1990;100(6):583-9. http://dx.doi. org/10.1288/00005537-19900600000006. PMid:2348735

2. Coppens F, Peene P, Lemahieu SF. Diagnosis and differential diagnosis of branchial cleft cysts by CT scan. J Belge Radiol. 1990;73(3):189-96. PMid:2380154
3. Oliai BR, Sheth $\mathrm{S}$, Burroughs $\mathrm{FH}$, Ali SZ. "Parapharyngeal space" tumors: a cytopathological study of 24 cases on fine-needle aspiration. Diagn Cytopathol. 2005;32(1):11-5. http://dx.doi.org/10.1002/dc.20154. PMid:15584054

4. Shin JH, Lee HK, Kim SY, Park HW, Khang SK, Choi CG, et al. Parapharyngeal second branchial cyst manifesting as cranial nerve palsies:
MR findings. AJNR Am J Neuroradiol. 2001;22(3):510-2. PMid:11237976.

5. Díaz-Manzano JA, Sánchez-Martínez $\mathrm{N}$, Iniesta-Alcázar J, Medina-Banegas A. Conservative surgical treatment of pharyngeal branchial cyst. Auris Nasus Larynx. 2008;35(1):1614. http://dx.doi.org/10.1016/j. anl.2007.04.009. PMid:17826930

Received: 12/14/2014 Accepted: 02/17/2015 